UDC 577.161.2:616.832-004.2

DOI: $10.21668 /$ health.risk/2019.3.07.eng

\title{
ENVIRONMENTAL FACTORS IN MULTIPLE SCLEROSIS, FOCUSING EXPOSURE TO ORGANIC SOLVENTS
}

\author{
I. Boström ${ }^{1}$, T. Riise ${ }^{2,3}$, K. Björnevik ${ }^{2,3}$, K.-M. Myhr ${ }^{2,3}$, \\ M. Pugliatti ${ }^{2,4}$, C. Wolfson ${ }^{5}$, A.-M. Landtblom ${ }^{1,6}$ \\ ${ }^{1}$ University of Linköping, Linköping, SE-581 83, Sweden \\ ${ }^{2}$ University of Bergen, 31, Kalfarveien, 5020, Bergen, Norway \\ ${ }^{3}$ The Norwegian Multiple Sclerosis Competence Center, Haukeland University Hospital, 5020, Bergen, 7804, Norway \\ ${ }^{4}$ University of Ferrara, Via Ludovico Ariosto 35, 44121 Ferrara, Italy \\ ${ }^{5}$ Research Institute of the McGill University Health Centre, Purvis Hall, 1020 Pine Avenue West Montreal, QC, Canada \\ ${ }^{6}$ Uppsala University, 75185 Uppsala, Sweden
}

Results obtained in previous studies on the relationship between exposure to organic solvents and risk of multiple sclerosis are not entirely consistent.

The aim of this study was to investigate the relationship between exposure to organic solvents and risk of multiple sclerosis and possible interactions between exposure to solvents and smoking; exposure to solvents and infectious mononucleosis; exposure to solvents and D-vitamin.

The case-control study on Evironmental Factors In Multiple Sclerosis (EnvIMS) was used. We examined two samples, the first one made up of 1.197 MS patients, and the second one, 2.361 healthy controls from Sweden and Norway; both group were matching in terms of their sex and age. We examined their exposure to organic solvents prior to the study; we also examined whether they had suffered from infectious mononucleosis, their outdoor activity (D-vitamin) and smoking status. The relationships between exposure to solvents and other risk factors were estimated as odds ratios (ORs) with $95 \%$ confidence interval (95\% CI) using logistic regression.

Exposure to organic solvents was found to be associated with an increased MS risk, OR 1.51 (95\% confidence interval (CI): 1.19-1.90; $p=0.001$ ), adjusted OR was 1.36 (95\% CI: 1.05-1.75; $p=0.020$ ). Adjusted ORs for different combinations including exposure to solvents and other risk factors such as smoking, infectious mononucleosis and D-vitamin showed an increased risk of MS. Among those who reported infectious mononucleosis there was no increased risk associated with exposure to solvents, OR 1.03 (95\% CI: 0.48-2.19).

The increased risk seems to be present only in individuals with unfavorable smoking status and low D-vitamin status.

Keywords: multiple sclerosis, risk factors, organic solvent, smoking, infectious mononucleosis, D-vitamin.

Several environmental factors have been demonstrated to increase the risk of developing multiple sclerosis (MS), such as Epstein Barr infection (EBV), smoking [1], low levels of vitamin D [2] and sun exposure, and obesity [3]. Landtblom et al also investigated if there were any appears to be an exposure time window of vulnerability for example regarding Epstein Barr infection after childhood and obesity in adolescence. For some risk factors there appears to exposure time window of vulnerability for example regarding Epstein

(C) Boström I., Riise T., Björnevik K., Myhr K.-M., Pugliatti M., Wolfson C., Landtblom A.-M., 2019

Inger Boström - PhD, Post doc, Division of Neurology, Department of Clinical and Experimental Medicine (e-mail: inger.bostrom@liu.se).

Trond Riise - Prof, Department of Global Public Health and Primary Care (e-mail: trond.riise@uib.no).

Kjetil Björnevik - PhD, Department of Global Public Health and Primary Care (e-mail: kjetil.bjornevik@uib.no).

Kjell-Morten Myhr - Prof, The Kristian Gerhard Jebsen Centre for MS-research, Department of Clinical Medicine (e-mail: kjell-morten.myhr@uib.no).

Maura Pugliatti - Ass Prof, Department of Biomedical and Specialty Surgical Science, Section of Clinical Neurology (e-mail: maura.pugliatti@unife.it).

Christina Wolfson - Prof, Department of Epidemiology and Biostatistics and Occupational Health (e-mail: christina.wolfson@mcgill.ca).

Anne-Marie Landtblom - Prof, Department of Neuroscience/Neurology (e-mail: anne-marie.landtblom@neuro.uu.se). 
Barr infection after childhood and obesity in adolescence [4].

Studies regarding solvents started early on with the observations of Amaducci in shoemakers in Florence. Eventually series of case control studies were performed, many of which seemed to suggest an odd ratio of about 2. Flodin [et al.] [5] and Landtblom [et al.] [6] saw an increased risk for MS in men due to occupational exposure to solvents, particularly in combination with welding in case-control studies.

An early meta-analysis of thirteen small studies in 1996 showed an association between organic solvents and MS in ten of them with about a two-folded risk of MS in exposed individuals [7]. They found no clinical differences between the two groups but there was a significant higher proportion of the exposed MS-patients who had hypointensity in basal ganglia on MRI compared to unexposed, although some of the unexposed MS-patients also had hypointensity in their basal ganglia [8].

Lantblom [et al.] compered MS-patients exposed to organic solvents with unexposed MS-patients to see if there was a difference in their metabolization of organic solvents. They investigated the occurrence of patients with GSTM1null and CYP2D6 poor metabolizers in the two groups but saw no difference between the exposed and unexposed group [9]. A big register study on occupational exposure in men between 1970 to 1980 saw no association between MS and occupational exposure [10]. A recent casecontrol study found no association between exposure to organic solvents and MS [11].

A review by Barragán-Martínez [et al.] in 2012 investigated the association between organic solvents and autoimmune diseases and saw an association between organic exposure and primary systemic vasculitis, systemic sclerosis and multiple sclerosis. Fifteen studies on MS and exposure to various organic solvents were included [12], about half of them was also included in the review by Landtblom et al in 1996. BarragánMartínez [et al.] found a slight but significantly increased risk of developing MS after exposure to organic solvents, the odds ratio calculated to $1,53(95 \% \mathrm{Cl}: 1,03-2,29)$ [12].

Since many anesthetics are related to organic solvents and trichloroethylene (TCE) previously have been used as an anesthetic [13] some groups have investigated if there is an association between exposure to anesthetics and an increased risk of MS. In 1988 Noseworthy reported two patients with TCE poisoning initially diagnosed as MS due to their fluctuation of symptoms. Both patients had normal MRI and clinic did not fully support MS [14]. A big study of marines exposed to mainly TCE and tetrachloroethylene in drinking water between 1975 and 1985 showed no association to MS. The levels of TCE were lower than the estimated exposure in industry at the same period and the time of exposure was relatively short [15]. Landtblom [et al.] noted a trend towards a higher cumulative incidence of MS in anesthetic nurses compered to teachers, only significant in the 1990-2000 strata and an almost two-fold non-significant risk compared to other nurses [16]. On the other hand, Stenager et al could not find an increased risk of MS among anesthetic nurses compared to the expected incidence in a matched population [17]. Nor did Hedström [et al.] in a later study where they also looked at anesthetic nurses exposed before 1985 as a separate group [18].

In a recently presented article by Hedström [et al.], a significantly increased risk of MS was shown after exposure of organic solvents, OR 1.5 (95\% CI 1.2-1.8). They have also analysed ORs for different combinations of genetic risk factors (DRB $1 * 15$ and

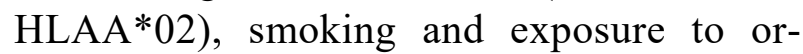
ganic solvents. An OR of 30.3 was seen when participants, carrying HLA-DRB $1 * 15$ and lacking HLA-A*02, were exposed to organic solvents and smoking in combination. However, it can be pointed out that the num- 
ber of cases and controls was quite little 40 respective 5 [19].

The purpose of this study was to analyze the risk for MS after exposure to organic solvents and possible interactions between solvent exposure and smoking; solvent exposure and EBV; solvent exposure and D-vitamin.

Methods. Study design. Our study is a part of the International multicenter casecontrol study of Environmental Factors in Multiple Sclerosis (EnvIMS). The EnvIMS aims to investigate the effects of self-reported exposure of risks, environmental issues and lifestyle in early stages of life to disease outbreaks in MS and to reveal possible risk differences between distinct populations using a common method. It has been carried out in well-defined geographic areas in Europe (Norway, Italy, Serbia and Sweden) and in Canada. Details of study design and methodology in EnvIMS have previously been reported by Magalhaes [et al.] [20].

Study population and area. The current study includes participants from Sweden and Norway aged 18 years or older at the time of selection. The cases were recruited from population-based MS registries. Four times as many age and sex frequency-matched controls were randomly selected from the population registries of each region under study. The response rates among the cases were $68 \%$ and $70 \%$ for Sweden and Norway respectively. The response rates among the controls were similar in Sweden and Norway (37\% and $36 \%$ ).

Exposure. Exposure information was collected through a novel, self-administered questionnaire. Ten questions about occupational exposure: engine oil, cutting oil, form oil, hydraulic oil, turbine oil, asphalt, drilling mud, crude oil, anesthetic gases and organic solvents (e.g. thinner, tri, trichloroethylene, lacquer naphtha, toluene, styrene, xylene or the like) were reported as «no», «don't know» and «yes». They reported age when exposure started, during how many years they were exposed and in what kind of work.
Smoking habits were reported as «ever» and «never» smoker, age at smoking initiation, total years of smoking and number of cigarettes per day in different age groups between 11 to 30 years.

EBV infection was measured as a positive history of infectious mononucleosis (IM) answered as «yes», «no» and «don't remember». They also reported which age period the disease was contracted.

As an indication of D-vitamin status there were questions about outdoor activity rated as «little (1)», «medium (2)», «pretty much (3)», «out almost all the time (4)», in age groups.

Statistical analysis. The association between disease and exposure was estimated as OR with $95 \%$ confidence interval $(95 \% \mathrm{CI})$ using logistic regression. All controls were randomly assigned an index age based on the distribution of age of disease onset in the cases. Events or reported behavior occurring after the age of MS onset or index age were not considered as exposure. The exposure time for solvents, smoking and IM must have occurred before onset of MS. All analyses were adjusted for age and sex.

To account for outdoor activity throughout adolescence the age periods «16-18» were used, which in previous studies from EnvIMS has shown been the most relevant MS risk. The values in the original variables (ranging from 14) were added and the new variable took value «Low D-vitamin» (rate 1-2) and «High D-vitamin» (rate 3-4).

Results. A total of 3558 people's answers are involved this study, 1197 cases and 2361 controls. The occupational questions about organic solvents were answered in total by 3457 individuals (97.2\%). «Yes» by 408 persons «No» by 2926, «Don't know» by 123 and there were 101 missing. Higher proportion of men than women has reported that they have been exposed of organic solvent.

In total the question about smoking was answered by 3461 persons (97.3\%). «Yes» 
by 1879 persons «No» by 1582 and there were 97 missing.

A total of 3447 (96.9\%) answered the question of IM, «Yes» by 403, «No» by 2872 and «Don't remember»172, missing 111. Outdoor activity answered by 3463 persons (97.3\%).

Exposure to organic solvents was found to be associated with MS in the pooled data from Sweden and Norway. The OR for risk of MS was 1.51 (95\% CI: 1.19-1.90, $\mathrm{p}=0.001)$, adjusted to IM, smoking and outdoor activity (vitamin D-level) the OR was 1.36 (95\% CI: $1.05-1.75, \mathrm{p}=0.020)$. In men the OR was 1.42 (95\% CI: 1.002.02, $\mathrm{p}=0.050$ ), in women 1.24 (95\% CI: 0.85-1.82, $\mathrm{p}=0.267$ ).

A calculation of the ORs associated with different combinations of solvent exposure and smoking, solvent exposure and IM; solvent exposure and D-vitamin showed an increased risk of MS. Cases with expo- sure to organic solvents and smoking the OR was $3.2(95 \% \mathrm{CI}: 2.36-4.36, \mathrm{p}=0.000)$; organic solvents and low D-vitamin had an OR 2.87 (95\% CI: 2.02-4.10, p = 0.000), Table 1.

Table 2 shows the effect of interaction providing the effect estimates for each of the three exposures variables (smoking, infectious mononucleosis (IM), D-vitamin level) stratified on exposure of organic solvents. The estimates for smokers and low D-vitamin show a significantly increased risk. In those who reported no history of IM there was a significantly increased risk.

Discussion. It is interesting to consider possible mechanisms that may be related to the effect of solvent exposure in MS. An effect on the blood brain barrier has been proposed as a cause of the increased risk, possibly opening for immunocompetent cells to enter the central

Table 1

Adjusted odd ratios of risk for multiple sclerosis with different combinations of exposure to organic solvents, smoking, infectious mononucleosis (IM) and D-vitamin

\begin{tabular}{|l|c|c|c|c|}
\hline \multicolumn{1}{|c|}{ Parameter } & Cases, $\mathrm{n}(\%)$ & Controls, $\mathrm{n}(\%)$ & OR $(95 \% \mathrm{CI})$ & $p$ \\
\hline Both countries & & & & \\
\hline No Solvents, No Smoking & $356(33,5)$ & $1041(48,7)$ & $1,00($ reference) & \\
\hline Yes Solvents, No Smoking & $38(3,6)$ & $98(4,6)$ & $1,12(0,75-1,67)$ & 0,582 \\
\hline No Solvents, Yes Smoking & $560(52,6)$ & $896(41,9)$ & $1,91(1,63-2,25)$ & 0,000 \\
\hline Yes Solvents, Yes Smoking & $110(10,3)$ & $103(4,8)$ & $3,21(2,36-4,36)$ & 0,000 \\
\hline No Solvents, No IM & $725(72,1)$ & $1689(83,7)$ & $1,00($ reference) & \\
\hline Yes Solvents, No IM & $116(11,5)$ & $172(8,5)$ & $1,49(1,15-1,94)$ & 0,003 \\
\hline No Solvents, Yes IM & $149(14,8)$ & $142(6,0)$ & $2,35(1,83-3,02)$ & 0,000 \\
\hline Yes Solvent, Yes IM & $16(1,6)$ & $16(0,7)$ & $2,17(1,08-4,39)$ & 0,030 \\
\hline No Solvents, High D-vitamin & $432(39,5)$ & $987(46,0)$ & $1,00($ reference) & \\
\hline Yes Solvents, High D-vitamin & $72(6,6)$ & $140(6,5)$ & $1,12(0,82-1,53)$ & 0,486 \\
\hline No Solvents, Low D-vitamin & $511(46,7)$ & $955(44,5)$ & $1,26(1,07-1,47)$ & 0,005 \\
\hline Yes Solvents, Low D-vitamin & $79(7,2)$ & $62(2,9)$ & $2,87(2,02-4,10)$ & 0,000 \\
\hline
\end{tabular}

Table 2

The association between smoking, infectious mononucleosis, D-vitamin level and risk of multiple sclerosis and cases exposed by solvents

\begin{tabular}{|c|c|c|c|c|c|c|}
\hline \multirow{2}{*}{ Data } & \multicolumn{7}{|c|}{ OR (95\% CI) for MS with history of solvents exposure } \\
\cline { 2 - 7 } & No Smoking & Yes Smoking & No IM & Yes IM & High D-vitamin & Low D-vitamin \\
\hline \multirow{2}{*}{$p$} & 1,17 & 1,62 & 1,48 & 1,03 & 1,11 & 2,31 \\
\cline { 2 - 7 } & 0,453 & 0,002 & 0,004 & 0,945 & 0,526 & 0,000 \\
\hline
\end{tabular}


nervous system. Since solvent exposure only seems noxious in smokers, one also must to consider the local inflammation caused by cigarette smoking as a mandatory variable for increasing the risk further.

In the Nordic countries, exposure to solvents is nowadays rather rare, because of hygienic regulations. Our finding is concerning a previous time period, and the participants are to certain extent, older people.
However, in other parts of the world, solvent exposure is still a valid health problem. In addition, our findings can say something about the mechanisms of MS pathogenesis.

Funding. The research was not granted any sponsor support.

Conflict of interests. The authors state there is no any conflict of interests.

\section{References}

1. Bjørnevik K., Riise T., Bostrom I., Casetta I., Cortese M., Granieri E., Holmøy T., Kampman M.T. [et al.]. Negative interaction between smoking and EBV in the risk of multiple sclerosis: The EnvIMS study. Mult. Scler., 2017, vol. 23, no. 7, pp. 1018-1024. DOI: 10.1177/1352458516671028

2. Bjørnevik K., Riise T., Casetta I., Drulovic J., Granieri E., Holmøy T., Kampman M.T., Landtblom A.M. [et al.]. Sun exposure and multiple sclerosis risk in Norway and Italy: The EnvIMS study. Mult. Scler., 2014, vol. 20, no. 8, pp. 1042-1049. DOI: 10.1177/1352458513513968

3. Wesnes K., Riise T., Casetta I., Drulovic J., Granieri E., Holmøy T., Kampman M.T., Landtblom A.M. [et al.]. Body size and the risk of multiple sclerosis in Norway and Italy: The EnvIMS study. Mult. Scler., 2015, vol. 21, no. 4, pp. 388-395. DOI: 10.1177/1352458514546785

4. Olsson T., Barcellos L.F., Alfredsson L. Interactions between genetic, lifestyle and environmental risk factors for multiple sclerosis. Nature, 2017, vol. 13, no. 1, pp. 25-36. DOI: 10.1038/nrneurol.2016.187

5. Flodin U., Soderfeldt B., Noorlind-Brage H., Fredriksson M., Axelson O. Multiple sclerosis, solvents and pets. Arch Neurol., 1988, vol. 45, no. 6, pp. 620-623. DOI: 10.1001/archneur.1988.00520300038015

6. Landtblom A.M., Flodin U., Karlsson M., Palhagen S., Axelson O., Soderfeldt B. Multiple sclerosis and exposure to solvent, ionizing radiation and animals. Scand J. Work Envion Health, 1993, vol. 19 , no. 6, pp. 399-404.

7. Landtblom A.-M., Flodin U., Soderfeldt B., Wolfson C., Axelson O. Organic solvents and multiple sclerosis: a synthesis of the current evidence. Epidemiology, 1996, vol. 7, no. 4, pp. 429-433.

8. Landtblom A.M., Thuomas K.A., Sjoqvist L., Flodin U., Nyland F.H., Soderfeldt B. Hypointensity in T2-weighted images of the basal ganglia in solvent-exposed patients with multiple sclerosis: clinical, MRI and CSF characteristics. Neurol. Sci., 2003, vol. 24, no. 1, pp. 2-9. DOI: 10.1007/s100720300014

9. Landtblom A.-M., Wastenson M., Ahmadi A., Soderkvist P. Multiple sclerosis and exposure to organic solvents, investigated by genetic polymorphisms of the GSTM1 and CYP2D6 enzyme systems. Neurol. Sci., 2003, vol. 24, no. 4, pp. 248-251. DOI: 10.1007/s10072-003-0148-5

10. Mortensen J.T., Bronnum-Hansen H., Rasmussen K. Multiple sclerosis and organic solvents. Epidemiology, 1998, vol. 9, no. 2, pp. 168-171.

11. Napier M.D., Poole C., Statten G.A., Ashley-Koch A., Marrie R.A., Williamson D.M. Heavy metals, organic solvents and multiple sclerosis: an exploratory look at gene-enviroment interactions. Arch. Environ. Occup. Health, 2016, vol. 71, no. 1, pp. 26-34. DOI: 10.1080/19338244.2014.937381

12. Barragan-Martinez C., Speck-Hernandez C.A., Montoya-Ortiz G., Mantilla R.D., Anaya J.-M., Rojas-Villarraga A. Organic solvents as risk factor for autoimmune diseases: A systematic review and meta-analysis. PLoS ONE, vol. 7, no. 12, pp. e51506. DOI: 10.1371/journal.pone.0051506

13. Flodin U., Landtblom A.-M., Axelson O. Multiple sclerosis in nurse anesthetics. Occup. Environ. Med., 2003, vol. 60, no. 1, pp. 66-68. DOI: 10.1136/oem.60.1.66

14. Noseworthy J.H. Trichloretylene poisoning mimicking multiple sclerosis. Le journal Canadien des sciences neurologiques, 1988, vol. 15, no. 1, pp. 87-88.

15. Bove F.J., Ruckart P.Z., Maslia M., Larson T.C. Evaluation of mortality among marines and navy personnel exposed to contaminated drinking water at USMC base Camp Lejeune: a retrospective cohort study. Environmental Health, 2014, vol. 13, 10 p. Available at: http://www.ehjournal.net/content/13/1/10 (03.05.2019) DOI: 10.1186/1476-069X-13-10 
16. Lantblom A.-M., Tondel M., Hjalmarsson P., Flodin U., Axelson O. The risk for multiple sclerosis in female nurse anaesthetisit: a register based study. Occup. Environ. Med., 2006, vol. 63, pp. 387-389. DOI: 10.1136/oem.2005.024604

17. Stenager E., Bronnum-Hansen H., Koch-Henriksen N. Risk of multiple sclerosis in nurse anaesthetists. Multiple sclerosis, 2003, vol. 9, no. 4, pp. 427-428. DOI: 10.1191/1352458503ms941xx

18. Hedstrom A.K., Hillert J., Olsson T., Alfredsson L. Exposure to anaesthetic agents does not affect multiple sclerosis risk. European Journal of Neurology, 2013, vol. 20, no. 5, pp. 735-739. DOI: 10.1111/ene.12098

19. Hedstrom A.K., Hossjer O., Katsoulis M., Kockum I., Olsson T., Alfredsson L. Organic solvents and MS susceptibility, Interaction with MS risk HLA genes. Neurology, 2018, vol. 91, no. 5, pp. e455-e462. DOI: $10.1212 /$ WNL.0000000000005906

20. Magalhaes S., Pugliatti M., Casetta I., Drulovic J., Granieri E., Holmøy T., Kampman M.T., Landtblom A.M. [et al.]. The EnvIMS study: Design and methodology of an international case-control study of environmental risk factors in multiple sclerosis. Neuroepidemiology, 2015, vol. 44, no. 3, pp. 173-181. DOI: $10.1159 / 000381779$

Boström I., Riise T., Björnevik K., Myhr K.-M., Pugliatti M., Wolfson C., Landtblom A.-M. Environmental factors in multiple sclerosis, focusing exposure to organic solvents. Health Risk Analysis, 2019, no. 3, pp. 60-65. DOI: 10.21668/health.risk/2019.3.07.eng

Received: 17.06 .2019

Accepted: 26.07.2019

Published: 30.09.2019 